\title{
The cost of antiretroviral treatment service for patients with HIVIAIDS in a central outpatient clinic in Vietnam
}

This article was published in the following Dove Press journal:

ClinicoEconomics and Outcomes Research

2I February 20I4

Number of times this article has been viewed

\author{
Long Thanh Nguyen' \\ Bach Xuan Tran² \\ Cuong Tuan Tran' \\ Huong Thi Le' \\ Son Van Tran'
}

'Authority of HIVIAIDS Control, Ministry of Health, Hanoi, Vietnam; ${ }^{2}$ Institute for Preventive Medicine and Public Health, Hanoi Medical University, Hanoi, Vietnam
Correspondence: Bach Xuan Tran Institute for Preventive Medicine and Public Health, Hanoi Medical University, No I, Ton That Tung, Hanoi, Vietnam Tel +84982228662

Email bach@hmu.edu.vn
Introduction: Antiretroviral treatment (ART) services are estimated to account for $30 \%$ of the total resources needed for human immunodeficiency virus (HIV)/acquired immunodeficiency syndrome (AIDS) control and prevention in Vietnam during the 2011-2020 timeframe. With international funding decreasing, determining the total cost of HIV/AIDS treatment is necessary in order to develop a master plan for the transition of ART services delivery and management. We analyzed the costs of HIV/AIDS treatment paid by both HIV programs and patients in a central outpatient clinic, and we explored factors associated with the capacity of patients to pay for this service.

Methods: Patients ( $n=315)$ receiving ART in the Department of Infectious Diseases at Bach Mai Hospital, Hanoi, Vietnam, were interviewed. Patient records and expenses were reviewed.

Results: The total cost of ART per patient was US\$611 (75\% from health care providers, 25\% from patients or their families). The cost of a second-line regimen was found to be 2.7 times higher than the first-line regimen cost. Most outpatients (73.3\%) were able to completely pay for all of their ART expenses. Capacity to pay for ART was influenced by five factors, including marital status, distance from house to clinic, patient's monthly income, household economic condition, and health insurance status. Most of the patients (84.8\%) would have been willing to pay for health insurance if a copayment scheme for ART were to be introduced.

Conclusion: This study provides evidence on payment capacity of HIV/AIDS patients in Vietnam and supplies information on ART costs from both provider and patient perspectives. In particular, results from this study suggest that earlier access to ART after HIV infection could dramatically reduce the overall cost of treatment.

Keywords: health care cost, human immunodeficiency virus infection, developing countries, opportunity cost, antiretroviral therapy

\section{Introduction}

Adding to their struggle with the human immunodeficiency virus (HIV)/acquired immunodeficiency syndrome (AIDS) epidemic, Vietnam and other developing countries are now facing the cutback of international funding for antiretroviral treatment (ART) for people living with HIV/AIDS. ${ }^{1}$ According to recommendations from the World Health Organization (WHO), ${ }^{2}$ all countries are aiming for the goal of $80 \%$ of all HIV/AIDS patients being provided with ART. However, with 67,057 HIV/ AIDS patients receiving ART in 2012, Vietnam has thus far fallen short of the goal, treating just $51.3 \%$ of people with HIV/AIDS, $94.1 \%$ of whom are under the financial support of an international program such as The President's Emergency Plan For AIDS Relief, the Global Fund to find AIDS, Tuberculosis and Malaria, and the 
project HIV/AIDS Prevention and Health Care for People with HIV/AIDS (LIFE-GAP). ${ }^{2,3}$ The challenge then, is not only to maintain the current level of ART provision, but also to expand treatment to new patients. The number of naïve patients registering for HIV/AIDS care is growing at a rate of approximately 950 patients per month, and $60 \%$ of these are enrolled in the first-line regimen of ART. ${ }^{3}$

Because most of the ART programs, including CD4+ cell testing and medication, are operated by international donors, financial funding from the Vietnam National Program for HIV/AIDS Control is negligible - less than $10 \%$ of total funding. ${ }^{4}$ A similar situation can be seen in other countries whose national HIV/AIDS programs contribute relatively little to the overall funding of ART, including Cambodia $(10 \%-11 \%)$ and Indonesia $(26 \%))^{5,6}$ Because of their dependence on international funding, the ART programs in countries and individual provinces without international projects, will encounter financial challenges in the near future, due to this dramatic reduction of external funding. ${ }^{4}$ Additionally, certain aspects of the health care system in Vietnam, such as limited health care insurance coverage for patients with HIV/AIDS, lack of integration of HIV services with the general health service delivery system, and low funding from governmental resources, are becoming barriers to treatment accessibility and delivery as well. ${ }^{1,4,7}$ Thus, even though international funding currently allows patients to access ART for free, assessment of financial capacity of HIV/AIDS patients will play a crucial role in preparing an appropriate ART policy once external financial support becomes unavailable or limited.

The costs of first-line and second-line ART regimens in several developing countries were outlined in a WHO summary report on an extensive program for HIV/AIDS treatment in 2004 and 2005. Although the cost of ART varied dramatically from country to country, the pattern in all these countries was that second-line ART was much more expensive. ${ }^{8}$ Further, whereas previous studies have examined the direct medical costs of ART, they failed to include additional components of patients' financial burden, such as travel expenses, lost work time, and other medications. ${ }^{9}$ The current study aimed to estimate the total cost of ART, including direct costs from health care practitioners, patients, and their families. Given the high total cost of treatment and the pending loss of international funding, ART will soon become an unbearably difficult financial burden for both the government and patients, necessitating the discussion of a copayment scheme for ART. Since such a copayment system would require payment contribution from patients, our analysis also examined the factors that influence patients' capacity to pay for ART.

\section{Materials and methods Study setting}

This study was conducted at the ART outpatient clinic in the Bach Mai Hospital, Hanoi, Vietnam. ART has been available with the financial support of LIFE-GAP since October 2009. This clinic has received a total of 904 people with HIV/AIDS and had provided ART for 713 patients (during the study, 518 patients received the first-line ART regimen and 25 received the second-line regimen). Patients receiving ART at this clinic can progress through five stages: testing for HIV confirmation, pretreatment, the first-line regimen, the second-line regimen, and finally, inpatient treatment. According to the Vietnam National HIV/AIDS care and treatment guideline, adopted from the WHO (2006), ${ }^{1,7}$ first-line regimens include zidovudine/ stavudine, lamivudine, plus nevirapine for main regimen, and zidovudine/stavudine, lamivudine, plus efavirenz for alternatives. Second regimens include zidovudine plus lamivudine or tenofovir plus lamivudine and lopinavir/ ritonavir or atazanavir. ${ }^{1,7}$ Since this study focused on the cost of outpatient treatment, only patients currently enrolled in pretreatment, the first-line regimen, or the second-line regimen of ART were included.

\section{Study design and data collection}

This was a cross-sectional study that used convenience sampling. We involved two patient groups: the first group consisted of pretreatment patients who had been managed by the outpatient clinic until at least December 31, 2011, and who had visited the clinic at least one time for testing or examination during the last 12 months. The second group included patients who had been treated with either the firstline or the second-line ART regimen between January 1, 2011 and December 31, 2011. After meeting these criteria, patients were excluded only if they refused to participate. We estimated that the necessary sample size was about 300 patients. We invited all participants who were present at the clinics during the period of the study and who agreed to participate in the interview, until we reached a sufficient number of respondents.

Medical records were reviewed and some general characteristics of each patient (identification in hospital, sex, age, risk factors for HIV acquisition) as well as clinical information (total time of ART counseling/examining, the number of months seen in 2011) were extracted. Using a 
checklist and a form that included highest viral load, latest CD4+ cell count, ART history, hepatitis C and/or hepatitis $\mathrm{B}$ coinfection, and pregnancy status, we selected medical records for further data collection on the basis of structured interviews with eligible patients. Payment capacity of patients was assessed using a single question "Would you be able to pay for the treatment costs?" The response options included "Can afford to pay full costs/Can afford to pay partial costs/Cannot afford to pay”. Opportunity costs were measured using the estimated number of working days lost by patients and caregivers.

\section{Statistical analysis}

Differences between groups were compared using chi-squared tests for categorical variables and Student's $t$-tests for continuous variables. Logistic regression was used to identify significant correlation of reported total costs with other predictor variables, including age, sex, and socioeconomic status.

\section{Ethical consideration}

Written informed consent was obtained in the local language, Vietnamese, from all study participants. For young participants aged 15-18 years, both patients and their caregivers were educated about the interview and gave informed consent. Research ethics approval was granted by the Institutional Review Board of the Administration of HIV/AIDS Control in Vietnam.

\section{Results}

\section{Characteristics of participants}

The overall study sample size was 315 patients, selected from the initial 601 medical records examined on the basis of the inclusion and exclusion criteria described (Table 1). Of these, $199(63.2 \%)$ were male and $116(36.8 \%)$ were female. The respondents ranged from 15 to 65 years old, with most being younger than 40 years of age $(83.8 \%)$ and the mean age at study entry being 35.1 years. A quarter of participants were engaged in drug use throughout the duration of the study, and $97.4 \%$ of those were male. Regarding their clinical stage of treatment, $13.7 \%$ patients were enrolled in pretreatment, $79.3 \%$ participants were receiving the first-line regimen, and $7.0 \%$ patients were receiving the second line regimen. Participants' mean duration of ART was 15 months, ranging from 4 months to 40 months. Mean CD4+ cell count of all patients at the time of study entry was $298 \mathrm{cells} / \mathrm{mm}^{3}$, ranging from $105 \mathrm{cells} / \mathrm{mm}^{3}$ to 300 cells $/ \mathrm{mm}^{3}$, and mean CD4+ cell count at the time of ART commencement was 140 cells $/ \mathrm{mm}^{3}$.
Table I Baseline demographic and clinical characteristics $(n=3 \mid 5)$

\begin{tabular}{|c|c|c|}
\hline Characteristic & $\mathbf{n}^{*}$ & $\% *$ \\
\hline Age, years (mean, SD) & 35.14 & \pm 7.92 \\
\hline$<40$ & 264 & 83.8 \\
\hline $40-60$ & 44 & 14.0 \\
\hline$>60$ & 7 & 2.2 \\
\hline \multicolumn{3}{|l|}{ Sex } \\
\hline Male & 199 & 63.2 \\
\hline Female & 116 & 36.8 \\
\hline \multicolumn{3}{|l|}{ Education } \\
\hline Illiterate/elementary school & 19 & 6.0 \\
\hline Secondary school & 130 & 41.3 \\
\hline High school & 103 & 32.7 \\
\hline Vocational training/university & 63 & 20.0 \\
\hline \multicolumn{3}{|l|}{ Marital status } \\
\hline Single & 49 & 15.6 \\
\hline Living with someone (couples/partners) & 212 & 67.3 \\
\hline Divorced/separated & 20 & 6.3 \\
\hline Widowed & 34 & 10.8 \\
\hline \multicolumn{3}{|l|}{ Distance from house to clinic } \\
\hline$<20 \mathrm{~km}$ & 93 & 29.5 \\
\hline $20-100 \mathrm{~km}$ & 133 & 42.2 \\
\hline$>100 \mathrm{~km}$ & 89 & 28.3 \\
\hline \multicolumn{3}{|l|}{ Occupation } \\
\hline Unemployed & 45 & 14.3 \\
\hline Farmer & 77 & 24.4 \\
\hline Worker & 45 & 14.3 \\
\hline Freelancer & 30 & 9.5 \\
\hline Business person & 41 & 13.0 \\
\hline Officer & 26 & 8.3 \\
\hline Other & 51 & 16.2 \\
\hline \multicolumn{3}{|l|}{ Economic status } \\
\hline Above middle & 204 & 64.8 \\
\hline Under middle & 11 & 35.2 \\
\hline \multicolumn{3}{|l|}{ ART stage } \\
\hline Pretreatment & 43 & 13.7 \\
\hline First-line regimen & 250 & 79.3 \\
\hline Second-line regimen & 22 & 7.0 \\
\hline Duration of ART, months (mean, SD) & 15 & \pm 8.0 \\
\hline \multicolumn{3}{|l|}{ Health insurance } \\
\hline Yes & 168 & 53.3 \\
\hline No & 147 & 46.7 \\
\hline
\end{tabular}

Note: *Unless otherwise indicated.

Abbreviations: ART, antiretroviral treatment; n, number; SD, standard deviation.

Regarding the economic situation of participants, two thirds of the subjects had a monthly income less than 3 million dong (equivalent to US \$150) and 14.3\% participants had no income at all. Including incomes from other family members, though, the majority of monthly household incomes ranged from 3 million dong to 6 million dong (38.1\%), and 34.6\% of households surpassed 6 million dong. Among households with a monthly income less than 6 million dong, total household expenditures came to $83.8 \%$ of income. Also, $53.3 \%$ of patients in this study had health insurance, indicating that the availability of health insurance for the poor is higher than expected. 


\section{Costs associated with ART for patients}

Table 2 indicates the component costs of ART from both health care providers' and patients' perspectives. The total cost of outpatient ART, including both medical and nonmedical costs, was US\$611/person/year, with $75 \%$ of the burden falling on health care funding sources and $25 \%$ on the patients' families. Cost of ART medication and of laboratory tests and X-rays accounted for $42.1 \%$ and $26.2 \%$ of the direct medical costs associated with ART, respectively. Meanwhile, travel spending and opportunity costs accounted for $48.9 \%$ and $24.4 \%$ of the cost to patients and their families. The cost of second-line regimen ART was 2.7 times higher than the first-line regimen, in part due to the fact that these medications cost 10 times more than the first-line medications.

Table 3 estimates the mean cost of ART from both health care and patient perspectives, with health care costs encompassing things like ART drugs, X-rays and testing, and patient costs including things like travel expenses, opportunity costs, and other medications. Factors that significantly affected the cost of treatment to patients - in terms of percentage of total monthly income - were the distance from house to clinic and the monthly household income. These factors had no influence on the health care costs, which increased from US\$346 for the first-line regimen to US\$369 for the second-line regimen, regardless of the patients' distance to the clinic and monthly household income. Conversely, the stage of treatment regimen had very little effect on the cost to patients.

\section{Capacity to pay for ART services}

This study examined the payment capacity to pay for ART among HIV/AIDS patients. The majority of participants (73.3\%) were able to pay completely for their expenditures incurred in accessing treatment, including costs such as travel and meals. Table 4 illustrates the correlations between payment capacity of ART outpatients and socioeconomic factors. Capacity to pay was found to be significantly correlated with education, marital status, living area, distance from house to clinic, monthly income of both the patient and their household, household economic condition, and monthly expenditure.

Table 5 displays the factors that affected payment capacity, as revealed by logistic regression to control for confounding variables and effect modification. The results suggest that marital status, distance to clinic, health insurance status, monthly income of patient, and monthly income of family were all significant factors that influenced patients' capacity to pay for treatment. Interestingly, those who had higher monthly income (both individual and household) were more willing to pay for ART than those with lower income (odds ratio $>2.00$ ), whereas participants who had health insurance were less willing to pay for expenditures of treatment.

When asked specifically about health insurance, most patients $(84.8 \%)$ would have been willing to pay for health insurance to cover their medical expenses if a copayment scheme of ART were introduced. On the other hand, only $61.4 \%$ of patients would have been willing to enroll in health

Table 2 Component costs of ART from health care providers and patients, by ART stage

\begin{tabular}{llll}
\hline Type of cost & $\begin{array}{l}\text { Pretreatment USD } \\
\text { (thousand VND) }\end{array}$ & $\begin{array}{l}\text { First-line regimen } \\
\text { USD (thousand VND) }\end{array}$ & $\begin{array}{l}\text { Second-line regimen } \\
\text { USD (thousand VND) }\end{array}$ \\
\hline $\begin{array}{l}\text { From health care providers } \\
\text { Health care staff }\end{array}$ & $69(1,432)$ & $69(1,432)$ & $69(1,432)$ \\
Amortization & $11(236)$ & $11(236)$ & $11(236)$ \\
Administration & $12(256)$ & $12(256)$ & $12(256)$ \\
Medical supplies & $17(355)$ & $17(355)$ & $17(355)$ \\
ART drugs & $0(0)$ & $101(2,113)$ & $1,049(21,845)$ \\
Non-ART drugs & $2(48)$ & $40(832)$ & $29(608)$ \\
Testing and diagnostic imaging & $73(1,521)$ & $110(2,294)$ & $159(3,312)$ \\
$\quad$ Total & $184(3,848)$ & $360(7,518)$ & $1,346(28,044)$ \\
From patients & & & $24(499)$ \\
Other medications & $1(19)$ & $18(375)$ & $82(1,701)$ \\
Travel costs & $21(431)$ & $90(1,868)$ & $19(398)$ \\
Meals & $5(112)$ & $19(389)$ & $\mathrm{n} / \mathrm{a}$ \\
Accommodation & $2(34)$ & $17(357)$ & $125(860)$ \\
Opportunity costs & $29(222)$ & $288(3,914)$ & $250(3,458)$ \\
$\quad$ Total & $58(8 \mid 8)$ & & \\
\hline
\end{tabular}

Note: Exchange rate in 2012: I USD =20,828 VND ( $>$ twenty thousands).

Abbreviations: ART, antiretroviral treatment; n/a: not applicable; USD, US dollars; VND, Vietnamese dong. 
Table 3 Mean cost of ART, adjusted by ART stage, distance to clinic, and monthly family income

\begin{tabular}{|c|c|c|c|}
\hline Predictors & $\beta$ & $P$-value & Mean cost in USD $(95 \% \mathrm{Cl})$ \\
\hline \multicolumn{4}{|c|}{ Cost from health care providers' estimation } \\
\hline Intercept & 352.58 & $<0.001$ & $297.52(249.11-345.93)$ \\
\hline \multicolumn{4}{|l|}{ ART stage } \\
\hline Pretreatment & -192.49 & $<0.001$ & I76.85 (99.29-254.4I) \\
\hline First-line regimen & -22.97 & $<0.69$ & 346.38 (3I I.48-38I.27) \\
\hline Second-line regimen & Ref & $\mathrm{n} / \mathrm{a}$ & $369.34(260.24-478.45)$ \\
\hline \multicolumn{4}{|l|}{ Distance from house to clinic } \\
\hline$<100 \mathrm{~km}$ & 29.30 & $<0.35$ & $312.17(264.63-359.72)$ \\
\hline$>100 \mathrm{~km}$ & Ref & $\mathrm{n} / \mathrm{a}$ & $282.87(216.99-348.75)$ \\
\hline \multicolumn{4}{|l|}{ Monthly family income } \\
\hline$>6$ million VND per month & 4.22 & $<0.89$ & $299.63(239.13-360.14)$ \\
\hline$<6$ million VND per month & Ref & $\mathrm{n} / \mathrm{a}$ & $295.41(243.14-347.67)$ \\
\hline \multicolumn{4}{|l|}{ Cost from patients' estimation } \\
\hline Intercept & $|46.5|$ & $<0.001$ & $109.06(|07.9|-\mid 10.22)$ \\
\hline \multicolumn{4}{|l|}{ ART stage } \\
\hline Pretreatment & -113.67 & $<0.001$ & $33.33(31.49-35.18)$ \\
\hline First-line regimen & -0.15 & $<0.91$ & |46.86 (|46.02-147.69) \\
\hline Second-line regimen & Ref & $\mathrm{n} / \mathrm{a}$ & $\mid 47.00(|44.4|-\mid 49.60)$ \\
\hline \multicolumn{4}{|l|}{ Distance from house to clinic } \\
\hline$<100 \mathrm{~km}$ & -2.36 & $<0.001$ & 107.89 (106.75-109.02) \\
\hline$>100 \mathrm{~km}$ & Ref & $\mathrm{n} / \mathrm{a}$ & II 0.24 (I08.68-III.8I) \\
\hline \multicolumn{4}{|l|}{ Monthly family income } \\
\hline$>6$ million VND per month & 3.35 & $<0.001$ & 110.74 (109.30-1 I2.18) \\
\hline$<6$ million VND per month & Ref & $\mathrm{n} / \mathrm{a}$ & 107.39 (106.14-108.63) \\
\hline
\end{tabular}

Note: Exchange rate in 2012: I USD =20,828 VND.

Abbreviations: ART, antiretroviral treatment; Cl, confidence interval; n/a: not applicable; Ref, reference group; USD, US dollars; VND, Vietnamese dong.

Table 4 Association between socioeconomic factors and payment capacity of ART outpatients

\begin{tabular}{|c|c|c|c|c|}
\hline & \multicolumn{3}{|c|}{ Have enough payment capacity? } & \multirow[t]{2}{*}{ OR $(95 \% \mathrm{CI})$} \\
\hline & $\begin{array}{l}\text { Yes } \\
\text { n (\%) }\end{array}$ & $\begin{array}{l}\text { No } \\
\text { n (\%) }\end{array}$ & $\begin{array}{l}\text { Total } \\
\text { n (\%) }\end{array}$ & \\
\hline \multicolumn{5}{|l|}{ Education* } \\
\hline Above high school & $53(84.1)$ & $10(15.9)$ & $63(100)$ & Ref \\
\hline Under high school & $178(70.6)$ & $74(39.4)$ & $252(100)$ & $2.203(1.064-4.563)$ \\
\hline \multicolumn{5}{|l|}{ Marital status ${ }^{\dagger}$} \\
\hline Married & $202(75.9)$ & $64(24.1)$ & $266(100)$ & Ref \\
\hline Single & $29(59.2)$ & $20(40.8)$ & $49(100)$ & $2.177(1.153-4.109)$ \\
\hline \multicolumn{5}{|l|}{ Living area $^{\dagger}$} \\
\hline Urban & I $28(79.5)$ & $33(20.5)$ & $161(100)$ & Ref \\
\hline Rural & $103(66.9)$ & $51(33.1)$ & $154(100)$ & $1.912(1.154-3.195)$ \\
\hline \multicolumn{5}{|c|}{ Distance from house to clinic* } \\
\hline$>100 \mathrm{~km}$ & $173(76.5)$ & $53(23.5)$ & $226(100)$ & Ref \\
\hline$<100 \mathrm{~km}$ & $58(65.2)$ & $5 I(33.1)$ & $89(100)$ & $1.745(1.023-2.975)$ \\
\hline \multicolumn{5}{|c|}{ Monthly income of patient only $y^{\ddagger}$} \\
\hline$<3$ million VND & I84 (80.3) & $45(17.9)$ & $229(100)$ & Ref \\
\hline$>3$ million VND & $47(54.7)$ & $39(45.3)$ & $86(100)$ & $3.393(1.987-5.795)$ \\
\hline \multicolumn{5}{|c|}{ Monthly income of entire family $y^{\ddagger}$} \\
\hline$>6$ million VND & $99(90.8)$ & $10(9.2)$ & $109(100)$ & Ref \\
\hline$<6$ million VND & $132(64.1)$ & $74(35.9)$ & $206(100)$ & $3.556(2.113-5.982)$ \\
\hline \multicolumn{5}{|c|}{ Monthly expenditure of entire family ${ }^{\ddagger}$} \\
\hline$<6$ million VND & $68(88.3)$ & $9(11.7)$ & $77(100)$ & Ref \\
\hline$>6$ million VND & $163(68.5)$ & $75(31.5)$ & $238(100)$ & $3.476(1.647-7.338)$ \\
\hline
\end{tabular}

Notes: $* P<0.05 ;{ }^{\dagger} P<0.02 ;{ }^{\ddagger} P<0.01$.

Abbreviations: ART, antiretroviral treatment; $\mathrm{Cl}$, confidence interval; n, number; OR, odds ratio; Ref, reference group; VND, Vietnamese dong. 
Table 5 Logistic regression of payment capacity and other predictors

\begin{tabular}{|c|c|c|c|c|}
\hline & $\beta$ & SE & OR & $P$-value \\
\hline \multicolumn{5}{|l|}{ Education } \\
\hline Above high school & 0.562 & 0.431 & 1.755 & 0.192 \\
\hline \multicolumn{5}{|l|}{ Under high school } \\
\hline \multicolumn{5}{|l|}{ Marital status } \\
\hline Married & 0.882 & 0.375 & 2.415 & 0.019 \\
\hline \multicolumn{5}{|l|}{ Single } \\
\hline \multicolumn{5}{|l|}{ Living area } \\
\hline Urban & 0.213 & 0.303 & 1.237 & 0.482 \\
\hline \multicolumn{5}{|l|}{ Rural } \\
\hline \multicolumn{5}{|c|}{ Distance from house to clinic } \\
\hline$<100 \mathrm{~km}$ & 0.647 & 0.314 & 1.909 & 0.039 \\
\hline \multicolumn{5}{|l|}{$>100 \mathrm{~km}$} \\
\hline \multicolumn{5}{|c|}{ Number of family members } \\
\hline$>3$ & 1.225 & 0.389 & 3.405 & 0.505 \\
\hline \multicolumn{5}{|l|}{$\leq 3$} \\
\hline \multicolumn{5}{|l|}{ Health insurance } \\
\hline Yes & -0.660 & 0.292 & 0.517 & 0.024 \\
\hline \multicolumn{5}{|l|}{ No } \\
\hline \multicolumn{5}{|c|}{ Monthly income of patient } \\
\hline$>3$ million VND & 1.225 & 0.389 & 3.405 & 0.002 \\
\hline \multicolumn{5}{|c|}{$<3$ million VND } \\
\hline \multicolumn{5}{|c|}{ Household economic condition* } \\
\hline Middle & 0.925 & 0.300 & 2.522 & 0.002 \\
\hline \multicolumn{5}{|l|}{ Poor } \\
\hline \multicolumn{5}{|c|}{ Monthly household expenditure } \\
\hline$>6$ million VND & 0.308 & $0.46 \mathrm{I}$ & $1.36 \mathrm{I}$ & 0.503 \\
\hline$<6$ million VND & & & & \\
\hline
\end{tabular}

Notes: *Rich is the reference group. Rich-Middle-Poor categories were defined by splitting the sample into 3 equal sub groups by their income per capita.

Abbreviations: OR, odds ratio; SE, standard error; VND, Vietnamese dong.

insurance if the current service fees, which require patients to pay for ART on their own, remained unchanged.

\section{Discussion}

This study generated a more comprehensive picture of the true cost of ART, including both the medical and nonmedical costs incurred by health care providers and the patients who access their services. The country of Vietnam is committed to treating $80 \%$ of HIV/AIDS patients, in accordance with the goals set by the WHO. ${ }^{3}$ However, because the government funds only a small percentage of the total cost of ART, and because international funding is likely to decrease in the near future, it is important to investigate the payment capacity of the HIV/AIDS patients themselves. ${ }^{1}$ This study presents some of the first evidence regarding the total cost of HIV/ AIDS treatment in Vietnam, including the nonmedical costs, as well as the capacity and willingness of the patients to pay for this treatment.

From the perspective of health care provision costs only, we found that patients in pretreatment stage incurred
US\$184/year (equivalent to $13.4 \%$ of the annual income of an average Vietnamese person in 2011), while ART costs of patients on the first-line regimen and second-line regimen were greater, at US\$360/year and US\$1,346/year, respectively. This was similar, but slightly less than the average expenditure for this treatment across the country as a whole, which was US $\$ 365 /$ year for the first-line regimen and US $\$ 1,464 /$ year for the second-line regimen. ${ }^{9}$ The medical costs associated with HIV/AIDS treatment in Vietnam, therefore, are likely to impose a significant financial burden on patients without any support from government or other funding sources. Additionally, in order to access and maintain treatment, patients have to incur many nonmedical costs, including travel costs, meals, accommodation, opportunity costs, and other medications. Indeed, even without the need to pay for ART itself, many patients face a significant financial burden just to access and sustain their treatment. ${ }^{1}$ The average out-of-pocket cost associated with these types of expenditures was approximately US\$153 per person-year, with the largest single cost being the cost of travel. Those in pretreatment paid approximately US\$58/year, which increased to US\$288/year in the first-line regimen stage of ART and US\$250/year in the second-line regimen stage. Given that pretreatment is appropriate for patients with better immunological status, and because pretreatment imposes a significantly lower financial burden on patients, an important implication of this study is that earlier access to treatment may limit total ART costs.

According to this study, the majority of ART costs come from medication (31.6\%), testing and X-rays (19.6\%), and travel costs $(12.2 \%)$. While this distribution reflects the current resource allocation of the Vietnamese government for HIV/AIDS control, the resources allocated are not sufficient to cover the cost of ART across the country. The resources of the Vietnam National Program for HIV/AIDS control currently account for only $5.9 \%$ of the total funding for ART, with the majority of the funding coming from international donors. ${ }^{4}$

Given this funding situation, HIV/AIDS patients currently have access to ART for free. However, this study found that a significant percentage of the total cost of ART comes from nonmedical expenses, including travel and opportunity costs, so that even with treatment available for free, $10.5 \%$ of participants were unable to pay for the expenditures required to access ART. Another $16.2 \%$ of participants were only partially able to pay for these expenses. One of the major contributing factors to this inability to pay was the patients' unemployment situation, which leads to low, and often unstable, incomes. 
It is clear that the health care system must be strengthened in such a way as to render the country's HIV control efforts sustainable. One solution that has been suggested is a copayment system for ART. However, in order for such a system to be effective, patients must be willing to pay for their share of services received. This study examined patients' capacity to pay for treatment, and found that it is strongly affected by five socioeconomic factors, including marital status, distance from house to clinic, monthly income, household economic condition, and health insurance status. Those participants living with a spouse were more willing to pay for treatment than those who were not, because patients living with a spouse were able to share the expenditure with their partner. Living further than $100 \mathrm{~km}$ from a clinic was another significant barrier to accessing ART, given the increased travel and accommodation costs; therefore, those who lived close to the clinic were more likely to pay for ART. Having higher income was also found to increase patients' capacity to pay for treatment, which is consistent with the fact that people respond more positively to the idea of paying for treatment if they are in a better economic condition.

One specific copayment strategy that was explored in this study is health insurance. Currently, ART medication is not covered by health insurance in Vietnam, which may be a significant deterrent for HIV/AIDS patients to be willing to pay for health insurance, despite the fact that health insurance may help to cover their additional medications and medical costs. Nonetheless, this study found that $53.3 \%$ of the patients surveyed had health insurance, indicating that the availability of health insurance for the poor is higher than may be expected. Interestingly, participants who had health insurance were less willing to pay for ART, perhaps because of the current lack of a copayment scheme for this treatment. Indeed, whereas only $61.4 \%$ would have been willing to enroll in health insurance with the current coverage and service fees, $84.8 \%$ would have been willing to pay for health insurance to cover their medical expenses if copayment for ART were introduced. This suggests that health insurance could be a potential tool in introducing copayment for ART, since many patients already pay for health insurance, and many others would be willing to do so.

Some of the strengths of this study include the large sample size of 315 participants (52.4\% of HIV patients at the Bach Mai Hospital), the combination of interview and retrospective review methods, and the fact that the baseline characteristics of participants were similar to those observed in other studies. Therefore this study provides a fairly reliable estimation of financial burden for ART patients, including health care service and opportunity costs from both patient and health care provider perspectives. However, several limitations should be noted. First, as this study was based on patients at a central hospital, this study is only representative of treatment at a central health care level. Consequently, the results of this study cannot easily be generalized to other health care settings. Another limitation of this study is that it offers few insights for inpatient treatment, as it focused only on the cost of outpatient treatment. Moreover, the estimated costs presented here excluded many indirect costs such as health care workforce, fixed properties, administration, and equipment operation fees. These costs were excluded due to the limit of time and resources and merit further investigation.

\section{Conclusion}

This study is one of the first to provide evidence on the payment capacity of HIV/AIDS patients in Vietnam, and it supplies information on ART cost from both provider and patient perspectives. Results of the study will potentially assist policymakers with resource allocation. For example, the finding that earlier access to ART could dramatically reduce the total cost of treatment could have implications for when to begin treatment for patients. In the current situation where ART is provided for free, most patients were able to pay completely for the expenditures associated with accessing treatment; however, payment capacity was limited for some patients even within this context. In light of the fact that international funding will likely be cut in the near future, it is imperative that new payment strategies be explored, in order to continue the patients' capacity to pay for treatment. We found that the majority of patients would be willing to pay for health insurance to cover their medical expenses if a copayment scheme for ART was introduced. This finding has immense implications for a strategy by which Vietnam could continue to sustain and expand its treatment of HIV/AIDS patients, even without the current level of international funding.

\section{Disclosure}

The authors report no conflicts of interest in this work.

\section{References}

1. Tran BX, Duong AT, Nguyen LT, et al. Financial burden of health care for HIV/AIDS patients in Vietnam. Trop Med Int Health. 2013;18(2) 212-218.

2. Nguyen DB, Do NT, Shiraishi RW, et al. Outcomes of antiretroviral therapy in Vietnam: results from a national evaluation. PLoS One. 2013;8(2):e55750.

3. Do TN, Nguyen TM, Do MH, et al. Combining cohort analysis and monitoring of HIV early-warning indicators of drug resistance to assess antiretroviral therapy services in Vietnam. Clin Infect Dis. 2012;54 Suppl 4:S306-S312. 
4. Tran BX. Willingness to pay for methadone maintenance treatment in Vietnamese epicentres of injection-drug-driven HIV infection. Bull World Health Organ. 2013;91(7):475-482.

5. Authority CNA. National AIDS Spending Assessment 2007-2008. Geneva, Switzerland: UNAIDS, 2009. Available at http://www. aidsdatahub.org/sites/default/files/documents/NASA_cambodia.pdf. Accessed May 1, 2013.

6. Center for Health Research University of Indonesia. Technical Report (Draft): AIDS Spending in Indonesia 2006-2007. Geneva, Switzerland: UNAIDS; 2008. Available at http://www.unaids.org/en/media/ unaids/contentassets/dataimport/pub/report/2008/20080603_nasa_ indonesia_06_07_en.pdf. Accessed May 1, 2013.
7. Tran BX, Ohinmaa A, Duong AT, et al. Cost-effectiveness of integrating methadone maintenance and antiretroviral treatment for HIV-positive drug users in Vietnam's injection-driven HIV epidemics. Drug Alcohol Depend. 2012;125(3):260-266.

8. Beck EJ, Miners AH, Tolley K. The cost of HIV treatment and care. A global review. Pharmacoeconomics. 2001;19(1):13-39.

9. Duong AT, Kato M, Bales S, et al. Costing analysis of national HIV treatment and care program in Vietnam. J Acquir Immune Defic Syndr. 2014;65(1):e1-e7.

\section{Publish your work in this journal}

ClinicoEconomics \& Outcomes Research is an international, peerreviewed open-access journal focusing on Health Technology Assessment, Pharmacoeconomics and Outcomes Research in the areas of diagnosis, medical devices, and clinical, surgical and pharmacological intervention. The economic impact of health policy and health systems organization also constitute important areas of coverage. The manuscript management system is completely online and includes a very quick and fair peer-review system, which is all easy to use. Visit http://www.dovepress.com/testimonials.php to read real quotes from published authors.

Submit your manuscript here: http://www.dovepress.com/clinicoeconomics-and-outcomes-research-journal 